\title{
Methodical Procedure For Designing of EFFICIENT LIGHTING SYSTEMS
}

\author{
Ruzena Kralikova \& Emil Wessely
}
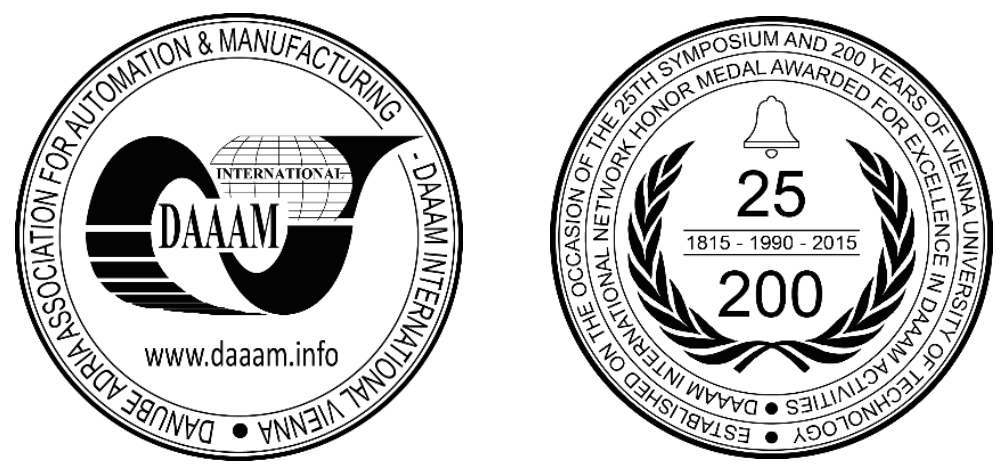

This Publication has to be referred as: Kralikova, R[uzena] \& Wessely, E[mil] (2016). Methodical Procedure for Designing of Efficient Lighting Systems, Proceedings of the 27th DAAAM International Symposium, pp.0066-0073, B. Katalinic (Ed.), Published by DAAAM International, ISBN 978-3-902734-08-2, ISSN 1726-9679, Vienna, Austria DOI: $10.2507 / 27$ th.daaam.proceedings.010

\begin{abstract}
Based on the lighting systems efficient utilization strategies analysis of lighting systems efficient utilization and through its synthesis with the options of intelligent control were for a design and calculation of lighting systems analyzes of the reference shop energy-saving lighting system designs were carried out. The results of the rationalization procedures and measures that have been made for the purpose of a reduction of energy demand of industrial operations lighting systems, were the basis for a development of a methodical procedure of designing of energy-efficient lighting systems in the sphere of engineering shops. The methodology presented in this paper is drawn up on the basis of valid legislation of the assessment and evaluation of lighting systems in a working environment with regard to ensuring of a visual comfort and creation of requested conditions for a visual activity, taking into account its energy efficiency.
\end{abstract}

Keywords: Methodology; energy; illumination; evaluation; design.

\section{Introduction}

Lighting is the way to a greener future. Sustainability meeting our needs today without compromising the resources future generations will need touches everything we do as a company. It's all about reducing environmental impact, a commitment that goes beyond our products to include how the products are used, how they are manufactured and how they are distributed. It even extends to the design of "greener" buildings. "Green building" incorporates environmentally responsible practices into the design of new construction and the renovation of existing buildings. Green facilities aren't just healthier for people and the planet. Using only as much light as is needed when it is needed is key to reducing energy consumption [7].

Characteristics of industry are large and high spaces, fixed working positions, long work periods, adverse conditions, various levels of illuminance, high bay lighting, central lighting control, restricted maintenance opportunities etc. It is one of the reason, why lighting accounts on average for about $15 \%$ of total electricity used in industry [11].

Recent developments in lighting technology combined with planned lighting control strategies can result in very significant cost savings, typically in the range of a third to a half of the electricity traditionally used for lighting [14,17]. Up to $75 \%$ of a conventional lighting cost is wasted cost - money spent on light that simply isn't required. An intelligent lighting system applies the correct level of light when needed to help meet carbon emissions targets, legislation requirements and dramatically reduce expenditure, whilst improving efficiency, comfort and safety [2], [16]. Energy- 
saving lighting for industry can reduce the impact of $\mathrm{CO}_{2}$ emissions on the environment, and save energy costs, as well as total costs and can ultimately contribute to improving of the quality and productivity of work [13].

Lighting can have other significance than just to light a dark room. It can improve the functions and the design of environment, improve occupational safety and create flexible spaces that are adapting themselves to the tasks according to the type of the carried out activity. Good lighting solutions delivers the right level of light at different times of the day and enhances people's sense of wellbeing, improving concentration, motivation and performance. Nowadays, with rising energy prices and tightening of legislation in the field of environment, energy-saving lighting can help businesses to achieve the objectives of sustainability [12].

\section{Methodical Procedure}

The methodology for designing of efficient lighting systems is drawn up on the basis of valid legislation of the assessment and evaluation of lighting systems in a working environment with regard to ensuring of a visual comfort and creation of requested conditions for a visual activity, taking into account its energy efficiency. The main parts of this methodology are divided into individual branches, by putting together of which, a sequence of steps and conclusions arise, which the methodology was developed for it [3].

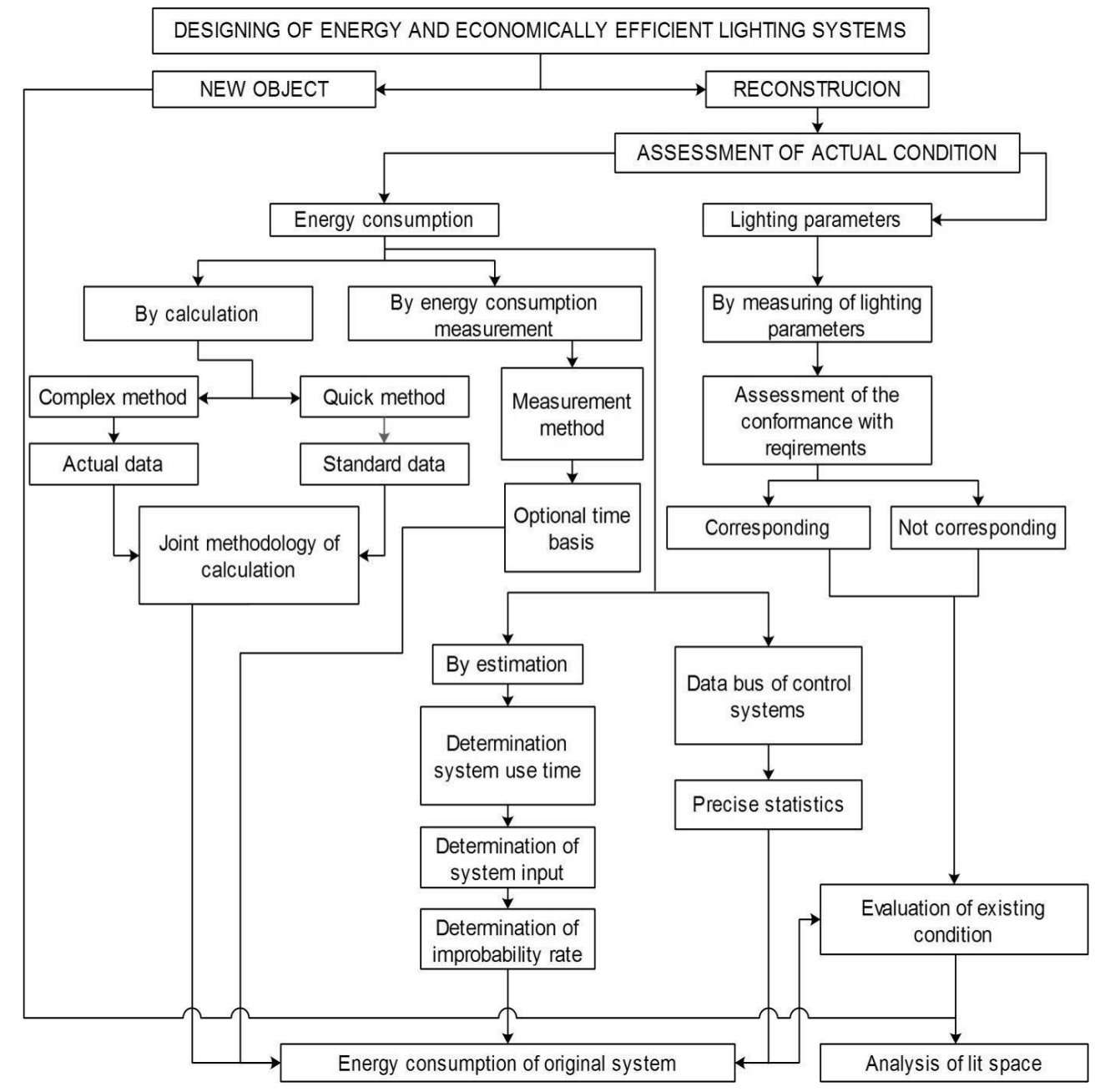

Fig.1. Diagram of assessing the current state of the objects it illuminates

The first step (Fig. 1) in the procedure of designing of energy and economically efficient lighting systems, should take into account the information if it is a newly implemented project or a reconstruction of a lighting system. In the case of a reconstruction, it is necessary to assess the actual condition of lighting in operation, from the point of view of energy as well as quality. It is needed to assess, whether the original lighting system meet legislative and normative requirements for the given space type and activity performed.

For the assessment of energy demanding character, several methods can be applied. Either the methods of calculation established by STN EN 15 193:2008 Energy performances of buildings [20]. Energy requirements for lighting, or it will be determined by energy consumption measurement or alternatively, by an estimation, where, however, it is needed to 
define the improbabilities of a result. The most accurate manner, how to determine the lighting energy consumption in industrial installations, is the utilization of collected data implemented in the systems of a lighting control [10].

\subsection{Analyse of the evaluation illuminated space}

Upon the current status evaluation, the next step in the process of an ecologisation of lighting systems is the analysis of lit space (Fig. 2), where in addition to dimensional and construction characteristics of a room, a classification of the assessed space into a correct workplace type will be made based on legal and normative regulations [3,4]. The correct classification of workplace by a type of operations performed plays an important role in the development of designs of energy-saving lighting systems, since the illuminance values, which the lighting system is to be dimensioned to, are based just on these documents [8].

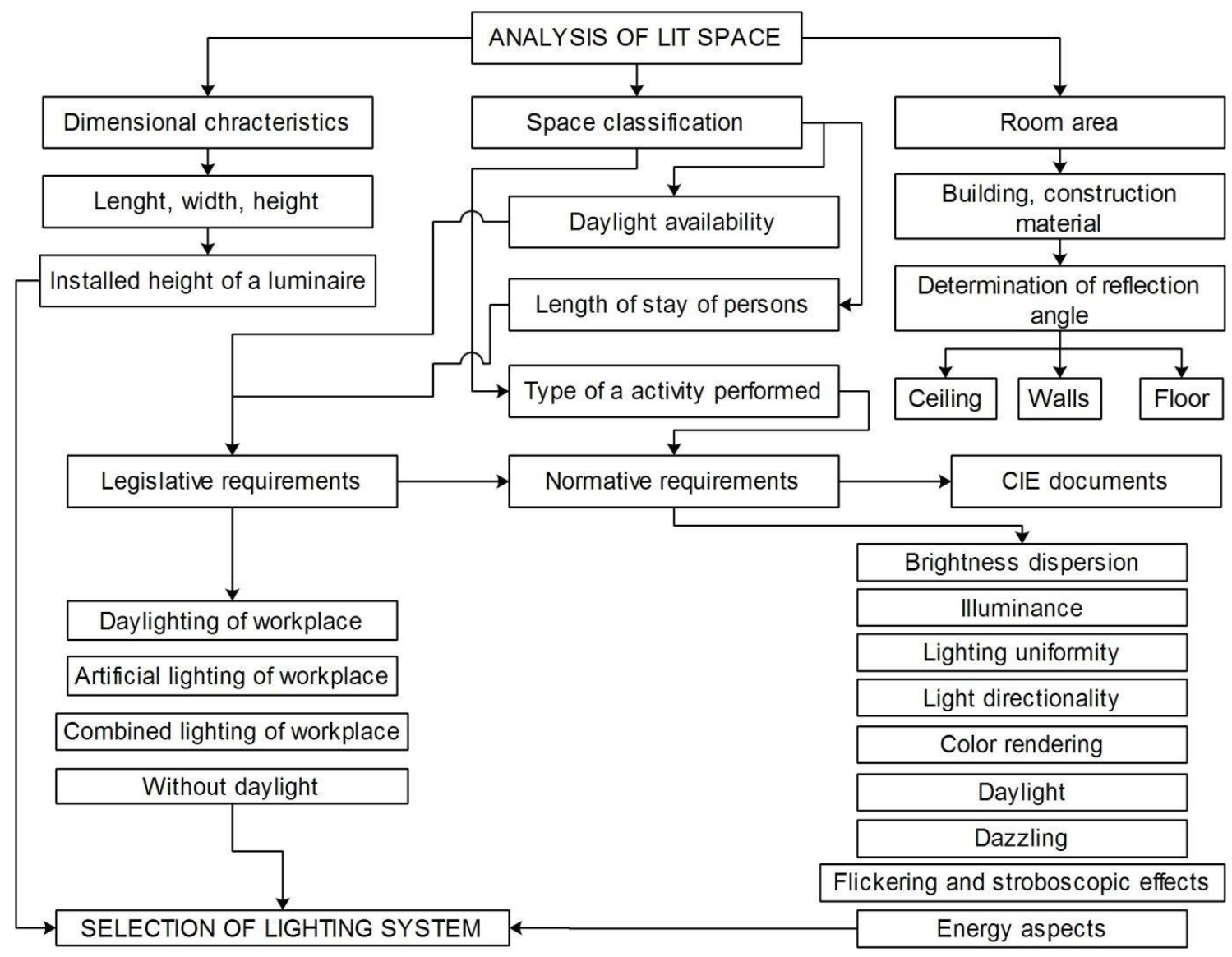

Fig. 2. Diagram of analyses evaluation illuminated space

\subsection{Choice of luminaire, technical devices and accessories}

The performance of a luminaire should be considered just as carefully as its cost. In the long term a well designed, well constructed luminaire will be cheaper than a poor quality unit; and the salient features of a good quality luminaire are [5]:

- Adequate screening of high luminance lamps to minimise discomfort and glare

- High light output ratio with the appropriate light distribution

- Ease of installation, cleaning and maintenance

By gradual defining of requirements related to a lighting system, taking occupational safety and health protection of employees into account, the selection of a lighting system was proposed as the next step, within the framework of the methodology (Fig. 3). Within this point, a careful analysis of parameters of technical devices of the lighting system (lamps, luminaires, ballasts, etc.) is needed, since just a suitable selection of technical devices and based on their parameters, it is possible to achieve the considerable energy savings in the process of the lighting systems ecologisation, while ensuring a maximum occupational safety and health protection of employees. A due attention is to be paid just to this step in the whole process of designing of energy-saving lighting systems.

The resulting material for further development of the lighting ecologisation project contains optional solutions of the technical devices the parameters of which were thoroughly compared and the most efficient of them were then selected. 


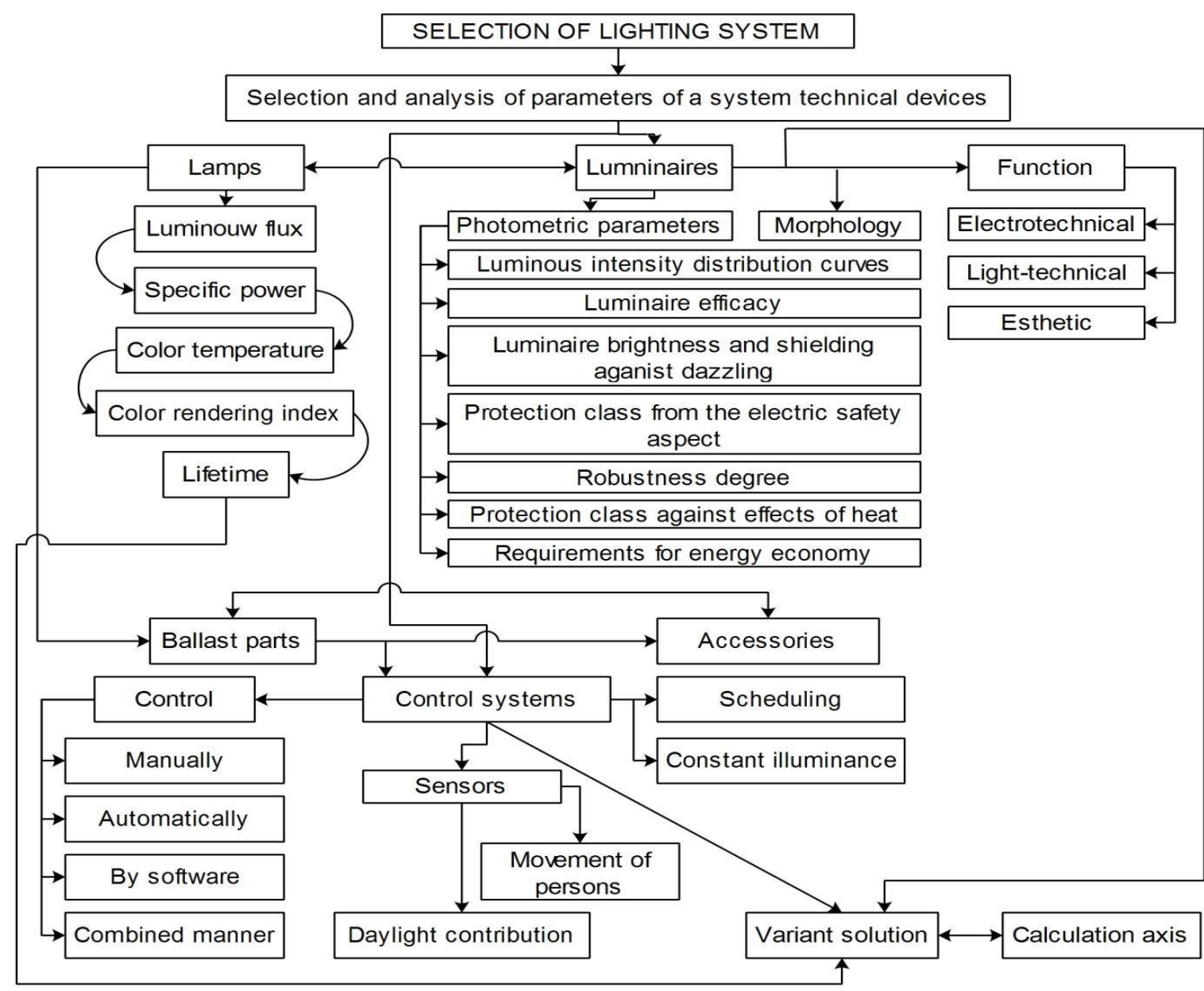

Fig. 3. Diagram choosing the media lighting system

Once the system of lighting has been selected, the most appropriate light source can then be chosen followed by the luminaire.

The following attributes should be studied when choosing the light source [19,21]:

- Light output (lumens)

- Total input wattage

- Efficacy (lumens per Watt)

- Lifetime

- Physical size

- Surface brightness/glare

- Colour characteristics

- Electrical characteristics

- Requirement for control gear

- Compatibility with existing electrical system

- Suitability for the operating environment

A number of factors also affect luminaire choice:

- Characteristics of the light source and control gear

- Luminaire efficiency (\% lamp light output transmitted out of the fixture)

- Light distribution

- Glare control

- Finish and appearance

- Size

- Accessibility of components for maintenance

- Ability to handle adverse operating conditions

- Aesthetics

- Thermal management. 


\subsection{The calculation of lighting system}

Upon defining of the characteristics of the system technical devices, for further advance in the ecologisation process, it is needed to choose an appropriate tool for a calculation of lighting system (Fig. 4). It is possible to carry out the calculation by various calculation methods or by designing and calculating computer tools intended for the elaboration of the lighting systems design and calculation. In this step, it is important to choose an appropriate type of the calculation and to take all circumstances related to the lighting system into account [1]. Very important parameter that is to be taken into consideration, is the maintaining factor value that is directly connected with a proposal of the maintenance schedule of the lighting system. The determination of a correct value of the maintenance factor has a large influence on total economy of the lighting system during the period of its utilization [8]. The applications of correct calculations and proposal results, in this stage of designing, in elaborated optional solutions which comply with the occupational and health protection requirements and, at the same time, are energy-efficient and economically profitable.

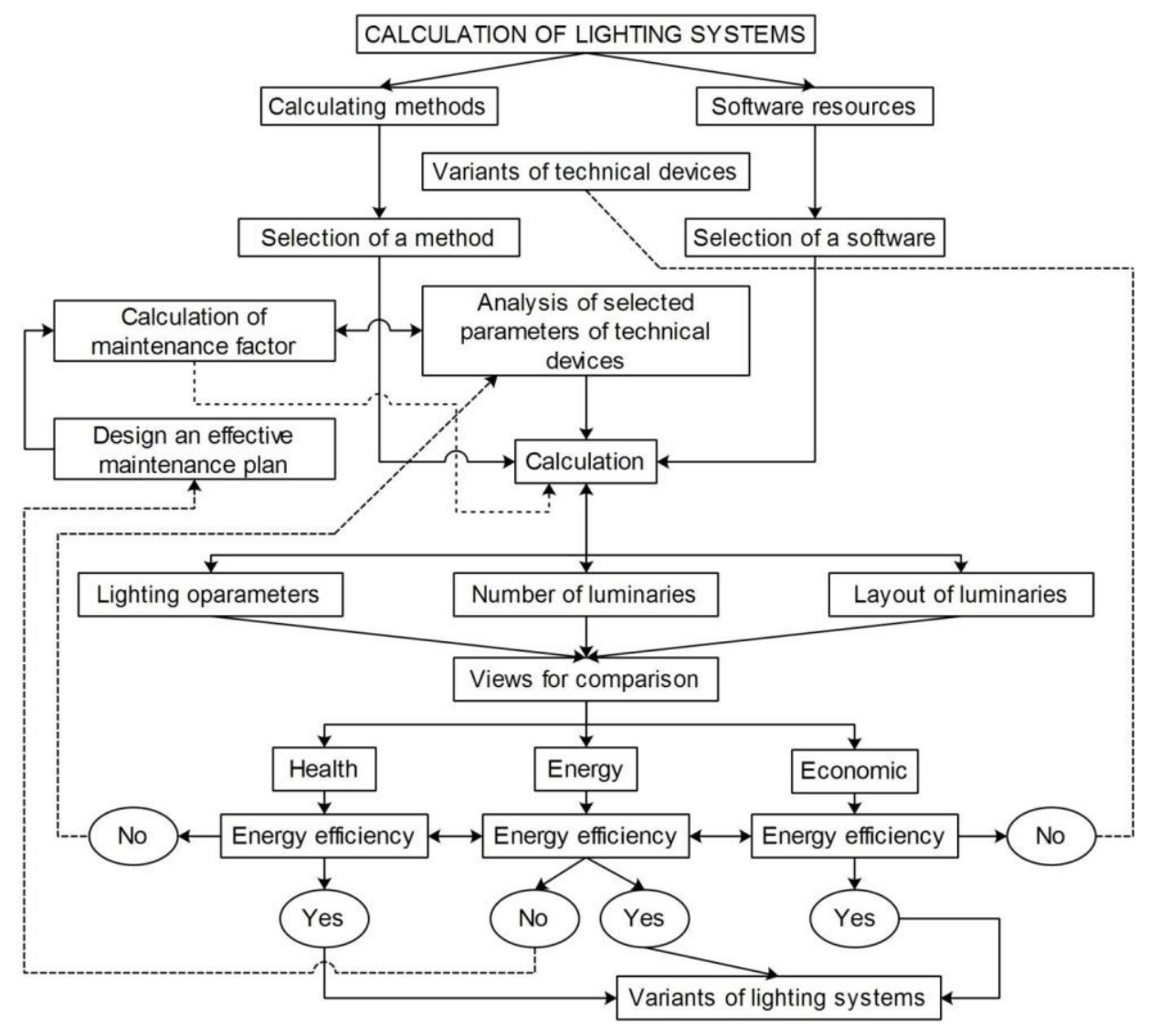

Fig.4. Diagram calculations of lighting systems

Lighting calculation methods fall into three broad categories:

1. Manual calculation methods

2. Three dimensional modelling

3. Visualisation

The advent of computer modelling enables a more flexible approach to lighting design and significantly increasing the information available to the designers. There are a wide range of computation methods for the calculation of different lighting aspects. These include complex methods for calculating the illuminance from a wide variety of shapes of luminous objects. The majority of these have now been superseded by computer programs. Photometric data for light sources and luminaires is commercially available to contribute to these calculations.

It is important in using a lighting calculation program that the output records the type of luminaire used, the location of the luminaires, the assumed lumen output of the lamp, the light loss factor and the aiming points. If this is not recorded you have only a picture of the installation and no way of making it a reality.

For visualisation exist more programs that create a perspective rendering of the space in levels of detail that vary from a block representation of the space, to photographic quality renderings, depending on the sophistication of the program and the level of detail of the interior are entered. The programs fall into two basic types:

- Flux transfer or radiosity calculations

- Ray tracing calculations 
Visualisation programs are a useful tool in the presentation of a design, as a tool for the designer to check that the design is consistent with his own visualisation of the space, and to model specific lighting solutions. The programs are mainly calculation tools and can show the designer how a specific design will look to assess the acceptability of a design. The output should include:

- Installation information - the type and location of all luminaires and the aiming information. The lamp details should be included, the specific catalogue number of photometric file etc.

- Light technical parameters - the illuminance, uniformity and other parameters that have been calculated to achieve the design.

- Verification information - adequate details to enable the lighting calculation to be verified. This should include the luminaire type, the photometric file, surface reflectances that were assumed, light loss factors, lumen output of lamps and mounting and aiming locations.

\subsection{The procedure for selecting the optimal alternative solutions}

In the last stage of the lighting systems designing process (Fig. 5), the elements of intelligent control systems are implemented into the optional proposals, which offer considerable energy sources savings based on the implementation of sensors and daylight contribution, human motion sensors, time regimes introduced or by a creation of the luminaire groups and therefore it is important, considering the given type of the workplace, to assess all possibilities of the lighting control and regulation in the installation [11].

In the final stage of the lighting systems ecologisation, particular options are compared from the point of view of energy efficiency and total investment and operational costs. In the case of a lighting system reconstruction, a comparison of the initial status and proposed option will be elaborated, taking energy savings and related financial savings, as well as attained lighting parameters of the system into account.

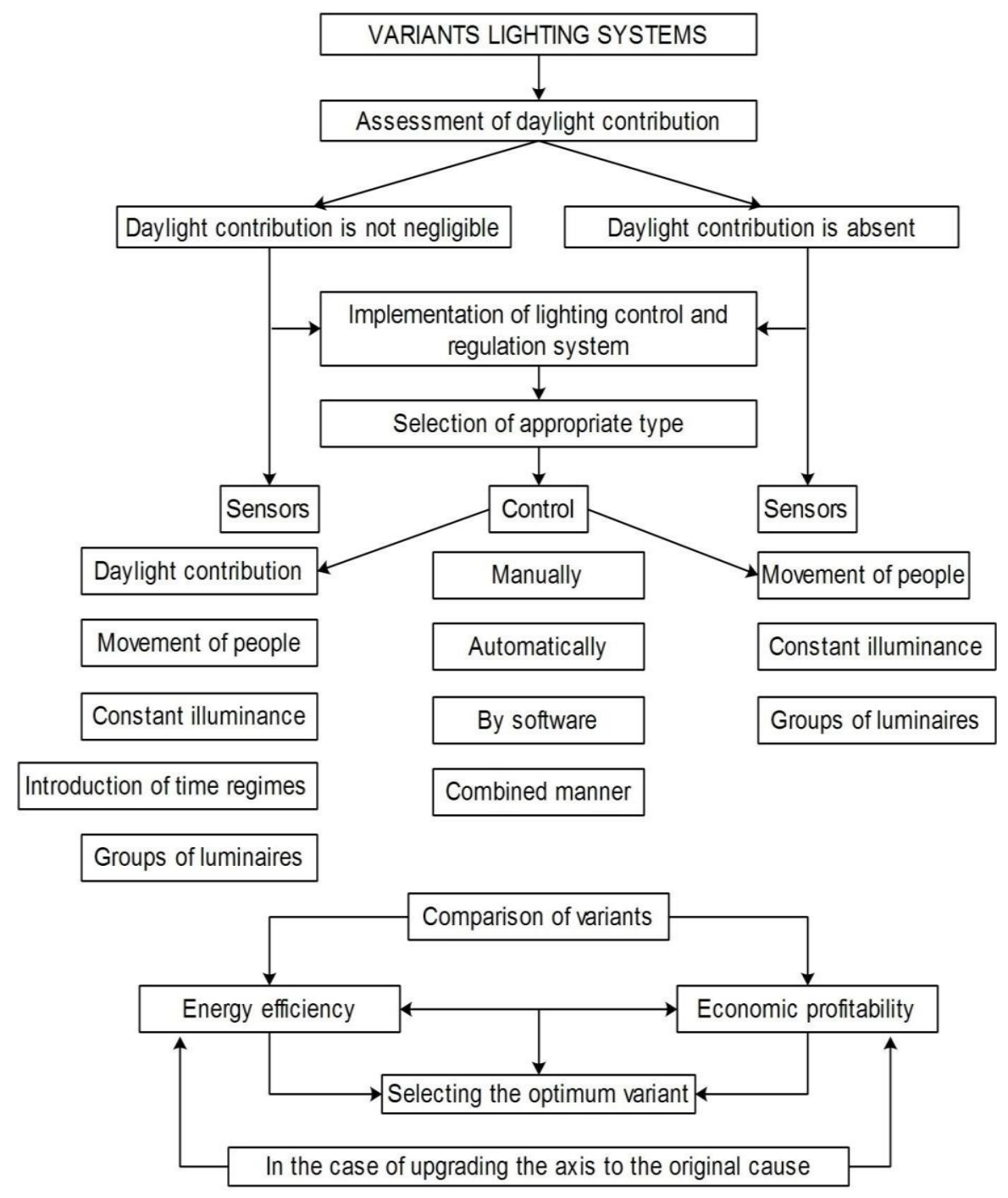

Fig. 5. Diagram selected optimum variants 
The effectiveness and efficiency of any lighting installation is affected as much by the control system as by the light sources and fixtures chosen [12]:

- Providing multiple switches to control the number of lights that come on at any one time. Using one switch to turn on all the lights in a large room is very inefficient.

- Placing switches at the exits from rooms and using two-way switching to encourage lights to be turned off when leaving the room.

- Using 'smart' light switches and fittings which use movement sensors to turn lights on and off automatically. These are useful in rooms used infrequently where lights may be left on by mistake, or for the elderly and disabled.

\section{Discussion and conclusion}

The presented contribution deals with actual issues, the search for rationalization measures in the energy consumption for lighting. Lighting systems is no small part of the share of total energy consumption, so it is necessary to look for energy savings opportunities in this area. In Slovakia, especially in industrial plants, a large amount of lighting systems that do not meet the requirements of energy efficiency, but what is worse, employees do not ensure an nor the minimum lighting requirements at work, which is the primary function of lighting workplaces. For that reason, is important to take design of lighting systems increased attention. However, not only after aspects of energy efficiency, which will ultimately brings also financial savings for consumers, but mainly with a view to ensuring a safe working environment for employees.

Nowadays $30 \%$ of energy used in building is wasted. On a personal, corporate or national level, lighting plays an important role in any energy saving strategy. Therefore, if we would to lower energy consumption we will reduce environmental footprint also. There are many good reasons to use energy-efficient lighting systems:

- Lower operating costs. The long-term savings can quickly repay the capital investment. Additionally, incentives may be available to owners to help offset the financial investment in new energy-efficient systems. These include allowing owners to use the money saved on energy bills to pay for the new system, utility incentive programs and government tax incentive programs.

- Increased property value - upgrading a new or existing facility with energy-efficient systems increases its fair value.

- Energy Attractiveness - energy efficient systems help to lowering operating costs.

- Improved workplace conditions. Many of today's lighting systems deliver more comfortable illumination and provide employees with the ability to select light levels that are suitable and comfortable for specific tasks. In many cases, employees chose lower light levels, which translate into greater energy savings.

- Installing energy-efficient systems provides an opportunity to identify the company as an environmentally conscious member of the community.

Based on a synthesis of theoretical assumptions and practical verification options to streamline lighting systems engineering operations is presented in the paper designing methodical process economic and energy-efficient lighting systems. Processed methodology served as the basis for drawing up. Within this methodology were conducted measurements of parameters of lighting in production areas of engineering establishments, which were found unsatisfactory. After analysing quantitative and qualitative parameters and variants with respect to options to achieve energy savings have been processed variants linked with the steering system and regulation lighting. For the draft to arrive at a solution that provided a reduction of energy consumption by half at double the amount of illuminance values in operation, which is how we assume sufficient results in search of rationalization measures with regard to the reducing energy consumption.

\section{Acknowledgments}

The research in this paper was supported by a grant „, Research of influence of chosen parameters of working environment on working power and productivity" VEGA - No 1/0537/2015 supported by Slovak Research and Development Agency (SRDA).

\section{References}

[1] Chin Kim Gan; Ahmad Farid Sapar; Yik Chee Mun \& Kuan Eng Chong (2013). Techno-Economic Analysis of LED Lighting (2013). A Case Study in UTeM's Faculty Building, Procedia Engineering, Vol. 53, 2013, pp. 208-216, ISSN 1877-7058.

[2] Csapo, A. \& Baranyi, P. (2012). A unified terminology for the structure and semantics of CogInfoCom channels In: Acta Polytechnica Hungarica Vol. 9, No. 1, 2012, pp. 85-105, ISSN: 1785-8860.

[3] Despotovic-Zrakic, M. ; Barac, D.; Bogdanovi Z.; Jovanic B.; Radenkovic B. (2014). Software environment for learning continuous system simulation In: Acta Polytechnica Hungarica Vol. 11, No. 2, 2014, pp. 187-202, ISSN: 1785-8860. 
[4] Dulina,L. \& Bartanusova, M. (2014). CAVE design using in digital factory, Proceedings of Procedia Engineering: international symposium on intelligent manufacturing and automation, Katalinic, B. (Ed.), DAAAM 2014, Vol. 100, pp. 291-298, ISSN 1877-7058, Vienna

[5] Durak, A.; Olguntürk, N. C.; Yener, C.; Güvenç, D. \& Gürçınar, Y. (2007). Impact of lighting arrangements and illuminances on different impressions of a room. Building and Environment, 42(10), 3476-3482.

[6] Gastermann, B. C.; Stopper, M. \& Katalinic, B. (2012). Adapting CONWIP Characteristics for Conventional Production Planning. In DAAAM International Scientific Book 2012, pp. 553-564, Editor B. Katalinic, Publisher by DAAAM International, ISBN 978-3-901509-86-5, Vienna, Austria

[7] Kovacic Lukman R.; Glavic, P.; Carpenter A. \& Virtič, P. (2016): Sustainable consumption and production Research, experience, and development - The Europe we want. In: Journal of Cleaner Production . August 2016, DOI: $10.1016 /$ j.jclepro.2016.08.049

[8] Kadir Amasyali \& Nora El-Gohary (2016). Building Lighting Energy Consumption Prediction for Supporting Energy Data Analytics, Procedia Engineering, Vol. 145, 2016, pp. 511-517, ISSN 1877-7058.

[9] Leppiman, A.; Kotka, T.; Kõrbe Kaare, K. \& Koppel, O.(2015). Decision-making framework for industrial-size datacenters. Proceedings of the International Conference of DAAAM Baltic "Industrial Engineering", 2015-January, pp. 237-242.

[10] Manlig, F.; Šlaichová, E.; Koblasa, F. \& Vavruška, J. (2014). Innovation of business processes by means of computer-aided simulation Applied Mechanics and Materials, 474, pp. 67-72.

[11] Micieta, B., Binasova, V. \& Kubinec, L.(2015): Information and Communication Technology Enabled Energy Efficiency In: DAAAM International Scientific Book 2015: Chapter 08 P. 087-096 ISBN: 978-3-902734-05-1.

[12] Micieta, B.; Zavodska, L.; Rakyta, M. \& Binasova, V. (2015). Sustainable concept for green logistics and energy efficiency in manufacturing. In: DAAAM International Scientific Book 2015. Chapter 33 p. 391-400 ISSN: 17269687 ISBN: 978-3-902734-05-1.

[13] Perlova,E.; Platonova,M.; Gorshkov, A. \& Rakova, X. (2015). Concept Project of Zero Energy Building, Procedia Engineering. Vol. 100. 2015. pp. $1505-1514$.

[14] Petek, J.; Glavič, P. \& Kostevšek, A. (2016). Comprehensive approach to increase energy efficiency based on versatile industrial practices In: Journal of Cleaner Production Vol. 112, 2016 , pp. 2813-2821, ISSN: 0959-6526.

[15] Sapi, J. ;Drexler, D. A. ; Harmati, I.; Szeles, A.; Kiss, B.; Sápi, Z. \& Kovács, L. (2013). Tumor growth model identification and analysis in case of C38 colon adenocarcinoma and B16 melanoma In: SACI 2013: 8th IEEE International Symposium on Applied Computational Intelligence and Informatics, Romania, pp 303-308, ISBN: 978-1-4672-6400-3.

[16] Satwiko, P. (2011). Pemakaian perangkat lunak Dialux sebagai alat bantu proses belajar tata cahaya In: Jurnal Arsitektur KOMPOSISI Vol. 9, No. 2, 2011, pp. 142-153.

[17] Sarkans, M.; Pikner, H.; Sell, R. \& Sonk, K. (2014). Energy efficiency monitoring system for technology mapping driven by FoF concept. Proceedings of the International Conference of DAAAM Baltic "Industrial Engineering", 2014-January, pp. 187-192.

[18] Vuorio, J.; Nikkilä, V.; Teivastenaho, V.; Peltola, J.; Partanen, J.; Kiviluoma, P. \& Kuosmanen P. (2014). Additive Manufacturing with UV Light Cured Resin, 9th International DAAAM Baltic Conference "INDUSTRIAL ENGINEERING" 24-26 April 2014, Tallinn, Estonia, pp. 317-322.

[19] EN 12464-1, Light and lighting - Lighting at work places - Part I: Indoor Work Places, European Standard.

[20] EN 15 193:2008 Energy performances of buildings. European Standard.

[21] European Directive 2006/25/EC, 2006. On the minimum health and safety requirements regarding the exposure of workers to risks arising from physical agents (artificial optical radiation). Official Journal of the European Union, L $114,38-59$ 